\title{
Sub-genomic RNA from dengue virus type 2 suppresses replication of dengue virus genomes and interacts with virus-encoded NS3 and NS5 proteins
}

Sai Wang1, Kitti W. K. Chan1, Kishore B. Naripogu1, Crystall M. D. Swarbrick1,3, John Aaskov2 and Subhash G. Vasudevan1,3*

\section{Table of Contents}

\begin{tabular}{|c|c|}
\hline Content & Page \\
\hline Figure S1. Nucleotide sequence of DENV2 DIP-296 RNA. & S2 \\
\hline $\begin{array}{l}\text { Figure S2. Sequence alignment of DENV2 DIP-296 with DENV 1, 3, and } 4 \\
\text { genomes. }\end{array}$ & S2 \\
\hline $\begin{array}{l}\text { Figure S3. Genome equivalent values (ratio of extracellular gRNA copy } \\
\text { number/mL to PFU/mL) from infected HuH-7 cells. }\end{array}$ & $\mathbf{S 2 - 3}$ \\
\hline $\begin{array}{l}\text { Figure S4. Characterization of RT-qPCR primers for specific detection of DIP- } \\
296 \text { RNA. }\end{array}$ & S3 \\
\hline $\begin{array}{l}\text { Figure S5. RNA electrophoretic mobility shift assay (REMSA) of the negative } \\
\text { control RNA (300 nt) with NS5 [A] or NS3 [B] analyzed on } 1.2 \% \text { agarose gel. }\end{array}$ & S4 \\
\hline Table S1. Real-time RT-qPCR primers for DENV 1-4. & S5 \\
\hline $\begin{array}{l}\text { Table S2. The mismatch rate (without considering the un-attempted sequences) } \\
\text { between DENV2 DIP-296 and DENV1, } 3 \text { and } 4 \text { genomes. }\end{array}$ & S5 \\
\hline $\begin{array}{l}\text { Table S3. Extracellular gRNA production from BHK- } 21, \mathrm{C} 6 / 36 \text { and HuH-7 cell } \\
\text { lines at } 24 \mathrm{~h} \text { post transfection with different amounts of DIP-296 RNA. }\end{array}$ & S5 \\
\hline $\begin{array}{l}\text { Table S4. Extracellular gRNA and plaque forming unit per } \mathrm{mL}(\mathrm{PFU} / \mathrm{mL} \text { ) of } \\
\text { DENV2 from HuH-7 and HuH-7.5 cells and calculation of the respective } \\
\text { genome equivalent values (ratio of extracellular gRNA copy number/mL to } \\
\text { PFU } / \mathrm{mL} \text { ). }\end{array}$ & S5-6 \\
\hline
\end{tabular}




\section{AGTTGTTAGTCTACGTGGACCGACAAAGACAGATTCTTTGAGGAAGCTAAGCTT AACGTAGTTCTAACAGTTTTTTAATTAGAGAGCAGATCTCTGATGAATAACCAAC GGAAAAAGGCGAGAAATACGCCTTTCAATATGCTGAAACGCGAGAGAAACCGC GTGTCAACTGTGCAGCAGAAA AAAACAGCATATTGACGCTGGGAAAGACCA GAGATCCTGCTGTCTCCTCAGCATCATTCCAGGCACAGAACGCCAGAAAATGG AATGGTGCTGTTGAATCAACAGGTTCT}

Figure S1. Nucleotide sequence of DENV2 DIP-296 RNA. 5' sequence of the DIP-296 is underlined; 5' UTR is shown in red; the start codon is highlighted in yellow indicating the $\mathrm{N}$ terminal of the capsid protein, which is shown in blue; the sequence of the 3' of DIP-296 is shown in orange. Besides, with the in-frame stop codon highlighted in green at the beginning of the 3' DIP-296, the open reading frame is translated into a 29-residue peptide "MNNQRKKARNTPFNMLKRERNRVSTVQQK".

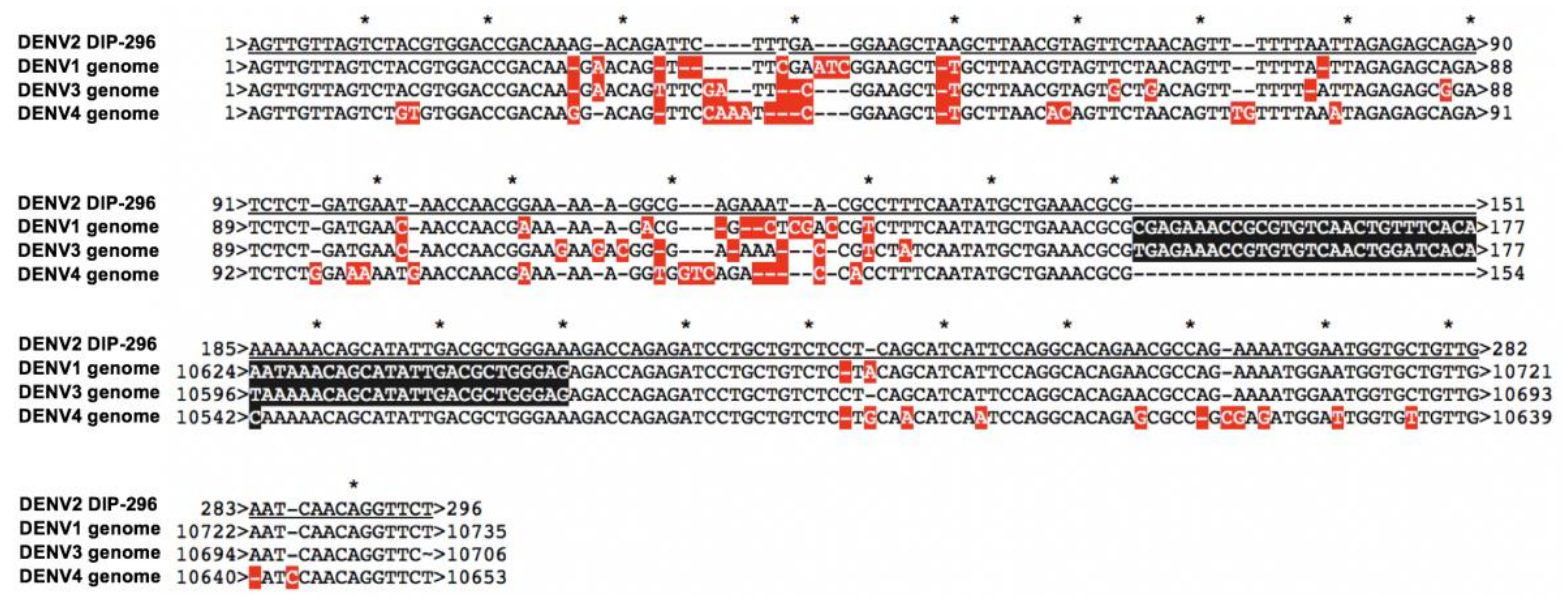

Figure S2. Sequence alignment of DENV2 DIP-296 with DENV 1, 3, and 4 genomes.

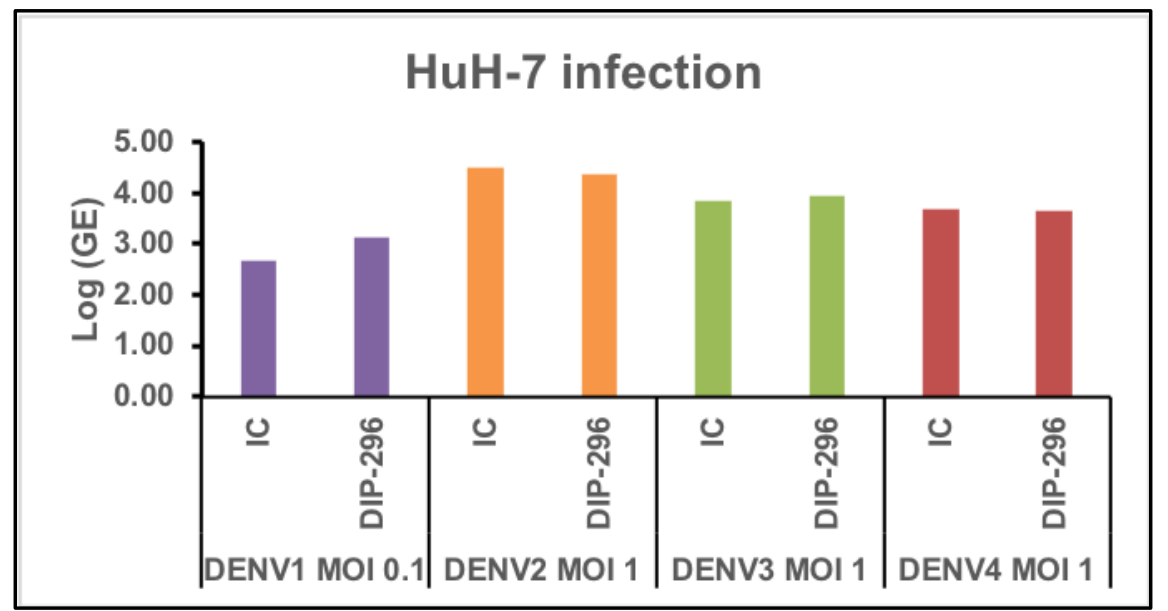

Figure S3. Genome equivalent values (ratio of extracellular gRNA copy number/mL to $\mathrm{PFU} / \mathrm{mL}$ ) from infected $\mathrm{HuH}-7$ cells. Infection with DENV 2, 3, and 4 was done at MOI 1, while infection with DENV 1 was at MOI 0.1. IC lane- infection control; DIP-296 lane- at 4hrs post infection, cells were transfected with $2 \mu \mathrm{g}$ of DIP-296 RNA. Both real-time RT-qPCR measurement of extracellular gRNA and plaque assay quantification of PFU were done at $24 \mathrm{hrs}$ post transfection (28hrs post infection). 


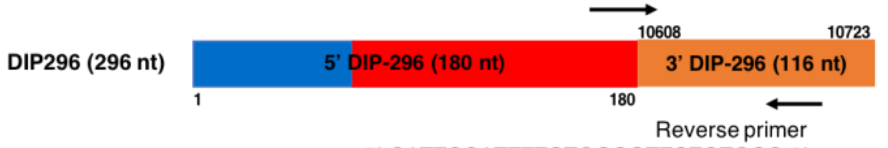

5'-CATTCCATTTTCTGGCGTTCTGTGCC-3'
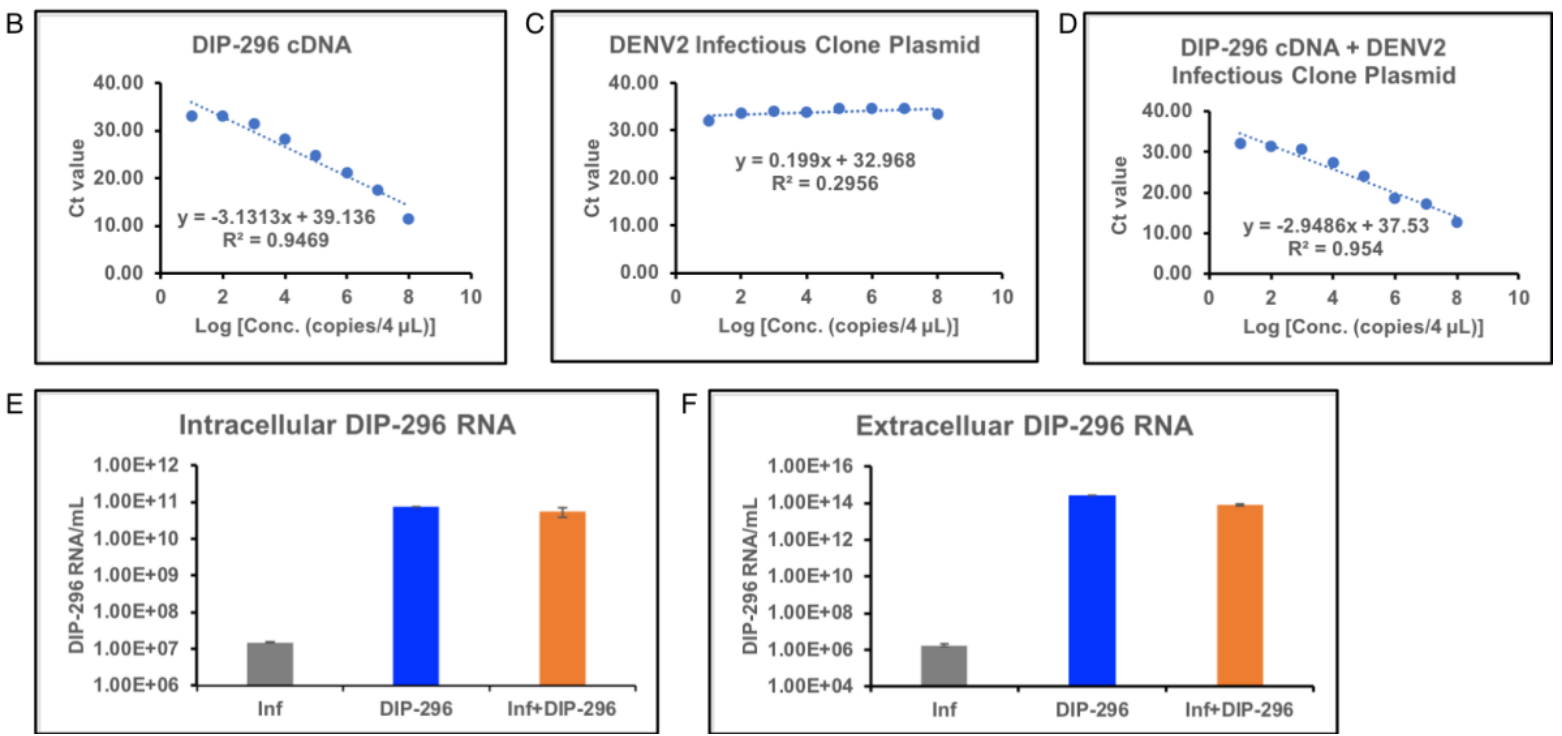

Figure S4. Characterization of RT-qPCR primers for specific detection of DIP-296

RNA. [A] Schematic showing the binding positions of forward and reverse primers designed for specific detection of DIP-296 RNA sequence, with the primer sequences indicated. [B-D] Test of primer efficiency, specificity and detection limit using different template- DIP-296 cDNA alone [B], DENV2 infectious clone plasmid [C], and mixture of DIP-296 cDNA and fixed amount of DENV2 infectious clone plasmid (10^8 copies/ $4 \mu \mathrm{L}$ ) [D]. Detection of intracellular [E] and extracellular [F] DIP RNA in HuH-7 cells that are infected with DENV2 and/or transfected with DIP-296 RNA as measured by RT-qPCR. Inf- infection control, HuH7 cells were infected by DENV2 at MOI 1; DIP-296- transfection control, $\mathrm{HuH}-7$ cells were transfected with $2 \mu \mathrm{g}$ of DIP-296 RNA; inf+DIP-296 RNA- at 4hrs post infection with DENV2 at MOI 1, cells were transfected with $2 \mu \mathrm{g}$ of DIP-296 RNA. RT-qPCR quantification of mRNA levels were done at $24 \mathrm{hrs}$ post transfection (28hrs post infection). 
A

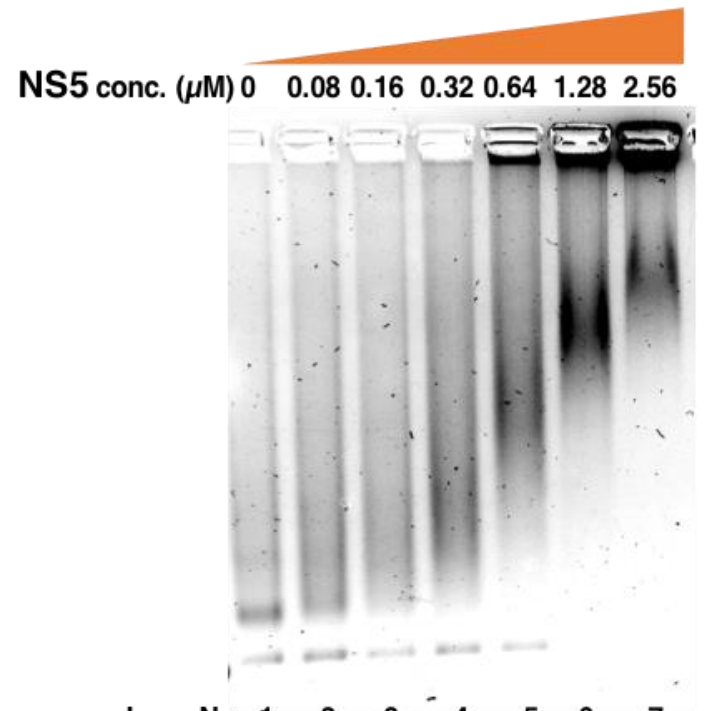

B

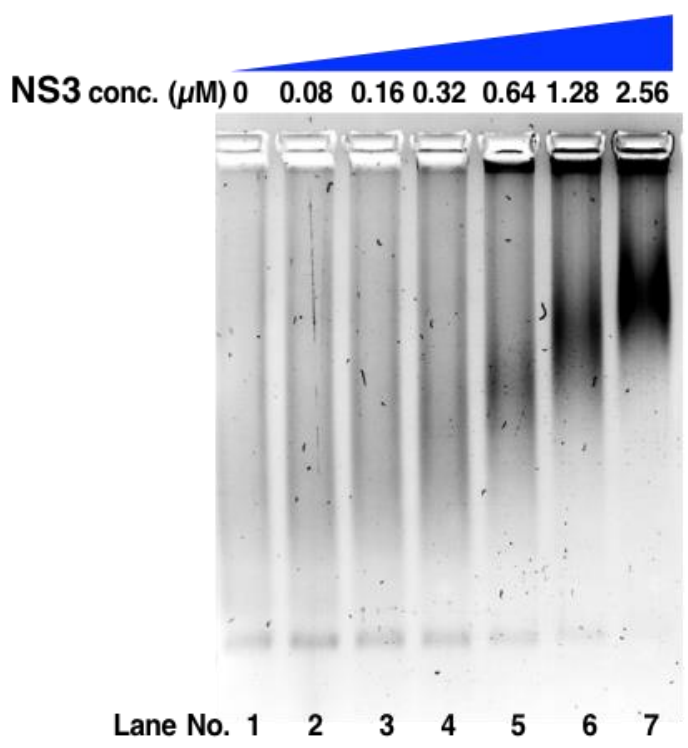

Figure S5. RNA electrophoretic mobility shift assay (REMSA) of the negative control RNA (300 nt) with NS5 [A] or NS3 [B] analyzed on 1.2\% agarose gel. Lane 1 in each image represents RNA alone in binding buffer. Samples on lane 2-7 are binding reactions of NS5 or NS3 with RNA at molar ratio of $0: 1,0.5: 1,1: 1,2: 1,4: 1,8: 1$ and 16:1, from left to right. Concentration of NS5 or NS3 is labelled on top of each lane. 
Table S1. Real-time RT-qPCR primers for DENV 1-4.

\begin{tabular}{|l|l|l|}
\hline Primer & Real-time RT-qPCR primers for DENV1, 2, 3, & \\
\hline DENV1 CDC_FP & CAAAAGGAAGTCGTGCAATA & Target gene \\
\hline DENV1 CDC_RP & CTGAGTGAATTCTCTCTACTGAACC & NS5 \\
\hline DENV2 CDC_FP & CAGGCTATGGCACTGTCACGAT & \multirow{2}{*}{ Envelop protein } \\
\hline DENV2 CDC_RP & CCATTTGCAGCAACACCATCTC & \multirow{2}{*}{ Pre-membrane } \\
\hline DENV3 CDC_FP & GGACTGGACACACGCACTCA & \multirow{2}{*}{ Pre-membrane } \\
\hline DENV3 CDC_RP & CATGTCTCTACCTTCTCGACTTGTCT & \\
\hline DENV4 CDC_FP & TTGTCCTAATGATGCTGGTCG & \\
\hline DENV4 CDC_RP & TCCACCTGAGACTCCTTCCA &
\end{tabular}

Table S2. The mismatch rate (without considering the un-attempted sequences) between DENV2 DIP-296 and DENV1, 3 and 4 genomes.

\begin{tabular}{|c|c|}
\hline Mis-match rate between DENV2 DIP-296 and DENV1, 3, 4 \\
DENV serotype & Mismatch rate \\
\hline DENV1 & $2.8 \%$ \\
\hline DENV3 & $4.1 \%$ \\
\hline DENV4 & $7.2 \%$ \\
\hline
\end{tabular}

Table S3. Extracellular gRNA production from BHK- 21, C6/36 and $\mathrm{HuH}-7$ cell lines at $24 \mathrm{~h}$ post transfection with different amounts of DIP-296 RNA.

\begin{tabular}{|c|c|c|c|c|c|c|}
\hline \multicolumn{2}{|c|}{ Extracellular gRNA production (genome copy numbers/mL) } \\
\hline $\begin{array}{c}\text { Amount of } \\
\text { transfected DIP- } \\
296 \mathrm{RNA} / \mu \mathrm{g}\end{array}$ & \multicolumn{2}{|c|}{ BHK-21 } & \multicolumn{2}{c|}{ C6/36 } & \multicolumn{2}{c|}{ HuH-7 } \\
\hline 0.5 & Mean & Std & Mean & Std & Mean & Std \\
\hline 1 & $2.40 \mathrm{E}+08$ & $2.59 \mathrm{E}+07$ & $2.11 \mathrm{E}+08$ & $6.85 \mathrm{E}+07$ & $1.03 \mathrm{E}+07$ & $5.00 \mathrm{E}+04$ \\
\hline 2 & $2.90 \mathrm{E}+08$ & $2.61 \mathrm{E}+07$ & $7.24 \mathrm{E}+08$ & $7.30 \mathrm{E}+07$ & $1.18 \mathrm{E}+07$ & $7.50 \mathrm{E}+04$ \\
\hline & $3.63 \mathrm{E}+08$ & $2.72 \mathrm{E}+07$ & $9.43 \mathrm{E}+08$ & $6.05 \mathrm{E}+07$ & $1.46 \mathrm{E}+07$ & $2.35 \mathrm{E}+05$ \\
\hline
\end{tabular}

Table S4. Extracellular gRNA and plaque forming unit per $\mathrm{mL}$ (PFU/mL) of DENV2 from HuH-7 and HuH-7.5 cells and calculation of the respective genome equivalent values (ratio of extracellular gRNA copy number $/ \mathrm{mL}$ to PFU $/ \mathrm{mL}$ ). Cells were infected with DENV2 at MOI 1, followed by transfection with $2 \mu \mathrm{g}$ of DIP-296 RNA at 4hrs post infection. Both real-time RT-qPCR measurement of extracellular gRNA and plaque assay quantification of PFU were done at $24 \mathrm{hrs}$ post transfection (28hrs post infection).

\begin{tabular}{|l|l|c|c|}
\hline \multicolumn{3}{|c|}{ DENV2 infection of HuH-7 and HuH-7.5 cells } \\
\hline \multirow{2}{*}{ Extracellular gRNA } & Cell line & Mean & Std \\
\cline { 2 - 4 } & $\mathrm{HuH}-7$ & $3.48 \mathrm{E}+07$ & $4.21 \mathrm{E}+04$ \\
\hline PuH-7.5 & $7.49 \mathrm{E}+07$ & $2.67 \mathrm{E}+06$ \\
\hline PFU/mL & $\mathrm{HuH}-7$ & $1.44 \mathrm{E}+03$ & $2.65 \mathrm{E}+02$ \\
\hline
\end{tabular}




\begin{tabular}{|c|c|c|}
\hline & HuH-7.5 & 1.13E+04 1.77E+03 \\
\hline \multirow{2}{*}{$\log (\mathrm{GE})$} & $\mathrm{HuH}-7$ & 4.4 \\
\hline & HuH-7.5 & 3.8 \\
\hline
\end{tabular}

